\title{
Preventing contrast-induced nephropathy: problems, challenges and future directions Richard Solomon
}

Address: University of Vermont College of Medicine, Burlington, VT 05405-0068, USA

Email: Richard Solomon - Richard.Solomon@vtmednet.org

Published: 13 May 2009

BMC Medicine 2009, 7:24 doi:10.1 186/1741-7015-7-24
Received: 23 April 2009

Accepted: 13 May 2009

This article is available from: http://www.biomedcentral.com/I74I-70I5/7/24

(c) 2009 Solomon; licensee BioMed Central Ltd.

This is an Open Access article distributed under the terms of the Creative Commons Attribution License (http://creativecommons.org/licenses/by/2.0), which permits unrestricted use, distribution, and reproduction in any medium, provided the original work is properly cited.

\begin{abstract}
Contrast-induced nephropathy is an injury to the kidney occurring as a result of exposure to intravascular contrast media. It results in both short- and long-term adverse events including mortality. Since treatment of the injury after it has occurred is ineffective, efforts to prevent the injury are the focus of investigators and clinicians alike. In this commentary, the pathogenesis and clinical relevance of contrast-induced nephropathy are reviewed. Prophylactic strategies are discussed with a focus on the use of meta-analysis of small single-center trials.
\end{abstract}

\section{Introduction}

Contrast-induced nephropathy (CIN) is an acute kidney injury associated with both short- and long-term adverse outcomes, including the need for renal replacement therapy, increased length of hospital stay, major cardiac adverse events, and mortality [1-3]. Since there is no effective therapy once injury has occurred, prevention is the cornerstone for all patients at risk for acute kidney injury. There is a small but growing body of evidence that prevention of the acute kidney injury is associated with a reduction in those later adverse outcomes. The article by Meier and colleagues, published this month in BMC Medicine, examines the prophylactic treatment of CIN using intravenous bicarbonate for prevention of CIN and the impact of such therapy on long term adverse events[4].

CIN involves at least two complementary pathophysiologic processes. First, contrast media is directly toxic to renal tubule cells, leading to mitochondrial dysfunction, generation of reactive oxygen species (ROS), and programmed cell death $[5,6]$. Second, contrast media reduces medullary blood flow further compromising a very tenuous balance between oxygen consumption and tissue oxy- gen availability in this critical area of the kidney. It is this part of the kidney that contains the last part of the proximal tubule and the thick ascending limb of Henle where a large proportion of sodium reabsorption occurs through active transport[7].

\section{Current limitations of diagnosis of CIN}

Our ability to diagnose CIN is limited by the lack of an appropriately sensitive and specific marker of kidney injury. Neutrophil gelatinase associated lipocalin, kidney injury molecule-1, interleukin-18 and other markers are currently being evaluated as reliable indicators of injury and predictors of adverse outcomes [8]. Until such validation occurs, changes in kidney function, specifically glomerular filtration rate (GFR), remain our only means of diagnosing CIN. In clinical practice, changes in GFR are estimated by absolute or relative changes in serum creatinine, that is, increases of $\geq 0.5 \mathrm{mg} / \mathrm{dl}$ or $\geq 25 \%$, respectively, occurring 48 to 72 hours after contrast exposure. Unfortunately, changes in serum creatinine can occur for reasons other than a decrease in GFR and thus are not specific for a decrease in GFR. Furthermore, because of the time lag between a fall in GFR and a rise in creatinine, the 
timing of creatinine measurement following contrast exposure can affect the sensitivity of the test [9]. Cystatin $\mathrm{C}$ has been advocated as a more sensitive marker of a fall in GFR [10-12].

\section{Current status of prevention therapies}

A variety of failed approaches has led to skepticism regarding our ability to effectively prevent the injury causing CIN. Systemically administered vasodilators, such as dopamine agonists, adenosine antagonists, prostaglandins, and endothelin antagonists, have been disappointing despite the rationale behind their use [13]. Antioxidants, such as $\mathrm{N}$-acetylcysteine, ascorbic acid, and bicarbonate, have enjoyed initial enthusiasm based upon single-center trials [14-16]. However, when considering data presented at society meetings and the increasing number of published negative trials, enthusiasm has waned and even meta-analyses have not found significant efficacy [17]. It is in this context that the article by Meier et al., published this month in BMC Medicine [4], is particularly valuable as it explores reasons for the heterogeneity in trial results.

\section{Bicarbonate therapy for prevention of CIN}

Bicarbonate therapy was initially explored because the generation of ROS is $\mathrm{pH}$ dependent through the HaberWeiss reaction [18]. It was argued that systemic alkalinization might reduce ROS generation and minimize the subsequent kidney injury. Subsequent studies with acetazolamide, which alkalinizes the urine while causing systemic acidification, showed that it is the urinary space that is the important site at which this pH effect acts [19]. Alkalinization of the urinary space is achieved very quickly with infusion of sodium bicarbonate because normally there is little bicarbonate in the urine. Even a small increase in serum bicarbonate of 1 to $2 \mathrm{mEq} /$ liter will result in the 'dumping' of bicarbonate into the urine in most patients. Such a change in serum is easily obtained with the infusion rates recommended in most of the CIN prevention trials $[14,20]$.

Bicarbonate therapy is readily available, inexpensive, and safe. The question is whether it is efficacious for prevention of CIN. Some single-center trials have found bicarbonate therapy to be efficacious while others have not. A previous metaanalysis of a small number of trials found bicarbonate to be beneficial only when not combined with other prophylaxis [21]. This heterogeneity in results leaves the physician confused at best and apathetic to prevention strategies at worst. Differences in selection criteria of patients, definition of outcome (CIN), protocols for administration of therapy, use of concomitant therapies, timing of follow-up serum samples, and so on may account for this heterogeneity. The article by Meier et al. tries to unravel some of these issues by looking at specific subsets of patients. For example, evidence of publication bias was found which the authors tried to overcome by including unpublished trials presented at major clinical meetings. Of particular clinical interest was the finding that bicarbonate therapy was most effective in patients who experienced urgent or emergency contrast exposure. Presumably this selects a group of patients who are less likely to receive any other form of prophylaxis for CIN. This is of great potential importance for the emergency room and cardiac catheterization laboratory. Bicarbonate therapy was also most effective in those receiving low osmolality contrast media compared with iso-osmolality contrast media. Low osmolality contrast is increasingly chosen because of its safety, lower costs, and higher iodine content [22].

\section{Future directions}

CIN needs to be redefined using markers of kidney injury that are sensitive, specific, and predictive of adverse outcomes. This will enable researchers to better address the question of how to prevent and/or treat this condition in the future. The most important question to be answered is whether prevention of kidney injury results in a change in short- and long-term adverse outcomes. Some prevention strategies have been associated with a reduction in longterm adverse events [23,24], while others have not [2527]. The meta-analyses by Meier et al. found that despite a reduction in the incidence of $\mathrm{CIN}$, bicarbonate therapy had no benefit on the need for dialysis or mortality. No matter how available, inexpensive, and safe a therapy, to find an important role in clinical therapeutics, it must improve the 'downstream' adverse outcomes, an as yet elusive goal for the prevention and treatment of CIN.

\section{Abbreviations}

CIN: contrast-induced nephropathy; GFR: glomerular filtration rate; ROS: reactive oxygen species

\section{Competing interests}

RS is a consultant to Bracco Diagnostics and Covidien, pharmaceutical companies which manufacture and sell contrast media.

\section{References}

I. Gruberg L, Mintz GS, Mehran R, Dangas G, Lansky AJ, Kent KM, Pichard AD, Satler LF, Leon MB: The prognostic implications of further renal function deterioration within $48 \mathrm{~h}$ of interventional coronary procedures in patients with pre-existent chronic renal insufficiency. J Am Coll Cardiol 2000, 36: I542-I 548.

2. McCullough PA, Sandberg KA: Epidemiology of contrast-induced nephropathy. Rev Cardiovasc Med 2003:S3-S9.

3. Rihal CS, Textor SC, Grill DE, Berger PB, Ting HH, Best PJ, Singh M, Bell MR, Barsness GW, Mathew V, Garratt KN, Holmes DR Jr: Incidence and prognostic importance of acute renal failure after percutaneous coronary intervention. Circulation 2002, 105:2259-2264.

4. Meier P, Ko DT, Tamura A, Tamhane U, Gurm HS: Sodium bicarbonate-based hydration prevents contrast-induced nephropathy: a meta-analysis. BMC Medicine 2009, 7:23. 
5. Romano G, Briguori C, Quintavalle C, Zanca C, Rivera NV, Colombo A, Candorelli G: Contrast agents and renal cell apoptosis. Eur Heart J 2008, 29:2569-2576

6. Bakris G, Lass N, Gaber AO, Jones JD, Burnett JC Jr: Radiocontrast medium-induced declines in renal function: a role for oxygen free radicals. Am J Physiol 1990, 258:FI I5-FI20.

7. Persson BP, Hansell P, Liss P: Pathophysiology of contrast medium-induced nephropathy. Kidney Int 2005, 68:14-22.

8. Han W, Waikar SS, Johnson A, Betensky RA, Dent CL, Devarajan P. Bonventre JV: Urinary biomarkers in the early diagnosis of acute kidney injury. Kidney Int 2008, 73:863-869.

9. Waikar SS, Bonventre JV: Creatinine kinetics and the definition of acute kidney injury. J Am Soc Nephrol 2009, 20:672-679.

10. Bachorzewsha-Gajewska H, Malyszko J, Sitniewska E, Malyszko JS, Pawlak K, Mysliwiec M, Lawnicki S, Szmitkowski M, Dobrzycki S: Could neutrophil-gelatinase-associated lipocalin and cystatin $C$ predict the development of contrast-induced nephropathy after percutaneous coronary interventions in patients with stable angina and normal serum creatinine values? Kidney Blood Press Res 2007, 30:408-4I5.

II. Devarajan P: Serum NGAL and cystatin $C$ as predictive biomarkers for acute kidney injury [abstract]. J Am Soc Nephrol 2006, I 7:404A.

12. Herget-Rosenthal S, Marggraf G, Husing J, Goring F, Pietruck F, Janssen $\mathrm{O}$, Philipp T, Kribben A: Early detection of acute renal failure by serum cystatin C. Kidney Int 2004, 66: I I I5- I I 22.

13. Kelly A, Dwamena B, Cronin P, Bernstein SJ, Carlos RC: Meta-analysis: effectiveness of drugs for preventing contrast-induced nephropathy. Ann Intern Med 2008, I 48:284-294.

14. Merten GJ, Burgess WP, Gray LV, Holleman JH, Roush TS, Kowalchuk G], Bersin RM, Van Moore A, Simonton CA III, Rittase RA, Norton HJ, Kennedy TP: Prevention of contrast-induced nephropathy with sodium bicarbonate: a randomized controlled trial. JAMA 2004, 29 I:2328-2334.

15. Spargias IK, Alexopoulos E, Kyrzopoulos S, lokovis P, Greenwood DC, Manginas A, Voudris V, Pavlides G, Buller CE, Kremastinos D, Cokkinos DV: Ascorbic acid prevents contrast-mediated nephropathy in patient with renal dysfunction undergoing coronary angiography or intervention. Circulation 2004, I I 0:2837-2842.

16. Tepel M, Giet M Van Der, Schwarzfeld C, Laufer U, Liermann D, Zidek W: Prevention of radiographic-contrast-agent-induced reductions in renal function by acetylcysteine. $\mathrm{N} \mathrm{Engl} \mathrm{J} \mathrm{Med}$ 2000, 343: $180-184$.

17. Gonzales D, Norsworthy KJ, Kern SJ, Banks S, Sieving PC, Star RA, Natanson C, Danner RL: A meta-analysis of $\mathbf{N}$-acetylcysteine in contrast-induced nephrotoxicity: unsupervised clustering to resolve heterogeneity. BMC Medicine 2007, 5:32-45.

18. Halliwell B, Gutteridge JMC: Role of free radicals and catalytic metal ions in human diseases: an overview. Methods Enzymo 1990, 186: I-85.

19. Pakfetrat M, Nikoo MH, Malehmakan L, Tabandeh M, Roozbeh J, Nasab MH, Ostovan MA, Salari S, Kafi M, Vaziri NM, Adl F, Hosseini $M$, Khajehdehi P: A comparison of sodium bicarbonate infusion versus normal saline infusion and its combination with oral acetazolamide for prevention of contrast-induced nephropathy: a randomized, double-blind trial. Int Urol Nephrol 2009 in press.

20. Solomon R: REMEDIAL: a role for sodium bicarbonate in the prevention of contrast-induced nephropathy. Nat Clin Pract Cardiovasc Med 2007, 4:474-475.

21. Navaneethan S, Singh S, Appasamy S, Wing RE, Sehgal AR: Sodium bicarbonate therapy for prevention of contrast-induced nephropathy: a systematic review and meta-analysis. Am J Kidney Dis 2009, 53:617-627.

22. Solomon R, Briguori C, Bettmann M: Selection of contrast media. Kidney Int 2006:S39-S45.

23. Marenzi G, Lauri G, Campodonico J, Marana I, Assanelli E, De Metrio M, Veglia F, Fabbiocchi F, Montorsi P, Bartorelli A: Comparison of two hemofiltration protocols for prevention of contrastinduced nephropathy in high-risk patients. Am J Med 2006, I 19:155-162.

24. Solomon R, Mehran R, Natarajan MK, Soucet S, Katholi RE, Staniloae CS, Sharma SK, Labinaz M, Gelormini JL, Barrett BJ: Contrastinduced nephropathy and long-term adverse events: cause and effect? Clin J Am Soc Nephrol 2009 in press.
25. Miner SE, Szavik V, Nguyen-Ho P, Richardson R, Mitchell J, Atchison D, Seidelin P, Daly P, Ross J, McLaughlin PR, Ing D, Lewycky P, Barolet $A$, Schwartz L: $\mathbf{N}$-acetylcysteine reduces contrast-associated nephropathy but not clinical events during long-term followup. Am Heart J 2004, I 48:690-695.

26. Mueller C, Buerkle G, Buettner H, Petersen J, Perruchoud AP, Eriksson $\mathrm{U}$, Marsch S, Roskamm H: Prevention of contrast mediaassociated nephropathy: randomized comparison of 2 hydration regimens in 1620 patients undergoing coronary angiography. Arch Int Med 2002, 162:329-336.

27. Stone GW, McCullough P, Tumlin J, Lepor NE, Madyoon H, Murray P, Wang A, Chu AA, Schaer GL, Stevens M, Wilensky RL, O'Neill WW: Fenoldopam mesylate for the prevention of contrastinduced nephropathy: a randomized controlled trial. JAMA 2003, 290:2284-229l.

\section{Pre-publication history}

The pre-publication history for this paper can be accessed here:

http://www.biomedcentral.com/1741-7015/7/24/prepub
Publish with Bio Med Central and every scientist can read your work free of charge

"BioMed Central will be the most significant development for disseminating the results of biomedical research in our lifetime. "

Sir Paul Nurse, Cancer Research UK

Your research papers will be:

- available free of charge to the entire biomedical community

- peer reviewed and published immediately upon acceptance

- cited in PubMed and archived on PubMed Central

- yours - you keep the copyright
BioMedcentral 